\section{P289 VARIABILITY IN GUIDELINES RECOMMENDATIONS FOR SCREENING OF GESTATIONAL DIABETES MELLITUS. A SYSTEMATIC REVIEW}

G Villanueva, J Bayón Yusta, M López-Argumedo. Basque Office for Health Technology Assessment, OSTEBA-EKU, Bilbao, Spain

\section{0:1136/bmjqs-2013-002293.241}

Background Gestational diabetes mellitus (GDM) is a frequent complication in pregnancy, however there is lacking agreement on international CPG on the best screening strategy: whom, when and how to screen. Following the HAPO study, the International Association of Diabetes and Pregnancy Study Group (IADPSG) recommended a new strategy consisting on a 1-step 2hour $75 \mathrm{~g}$. oral glucose tolerance test.

Objectives To systematically review the evidence that compares alternative tests for diagnosis of GDM, in terms of maternal and infant health and costs.

Methods MEDLINE, EMBASE, EBM reviews and NHS EED were searched. Studies comparing the IADPSG guidelines with other strategies were retrieved. Besides, recommendations currently in place in different countries were summarised.

Results Eleven studies were selected. The results showed that the IADPSG criteria nearly threefold GDM prevalence. Women who fulfilled IADPSG criteria but were normal using other criteria experienced significantly higher adverse outcomes (macrosomia, preterm delivery, neonatal hypoglycaemia and preeclampsia). Although the IADPSG screening strategy was more costly, considering the long-term maternal benefits and the neonatal outcomes it might be cost-effective.

Discussion Implementing the IADPSG criteria will increase GDM diagnosis and this may pose a strain on health care systems, but it is also an opportunity to reduce adverse outcomes for mother and child. In fact, the IADPSG strategy appeared to be cost-effective strategy under certain conditions. Further large well-designed trials are needed to determine the best strategy.

Implications for Guideline Developers/Users Considering the high inconsistency across guidelines the new IADPSG screening strategy may outdate current strategies proposed on CPG.

\section{P290 ATTITUDES OF PROFESSIONALS INVOLVED IN DEMENTIA CARE TOWARDS ADVANCE DIRECTIVES AND ITS IMPACT ON THEIR ADHERENCE TO GUIDELINE RECOMMENDATIONS}

${ }^{1} \mathrm{G}$ Villanueva, ${ }^{1} \mathrm{M}$ López-Argumedo, ${ }^{2} \mathrm{E}$ Reviriego1, C Gómez Poveda, ${ }^{3} \mathrm{E}$ Aguirreche Ollo, ${ }^{4}$ A Elizondo, ${ }^{1} \mathrm{R}$ Fuentes Gutiérrez, 'L Galnares-Cordero. 'Basque Office for Health Technology Assessment, OSTEBA-EKU., Bilbao, Spain; ${ }^{2}$ Residencia Fundación Miranda., Bilbao, Spain; ${ }^{3}$ Centro de rehabilitación neuropsicológica Arrigunaga, Barakaldo, Spain; ${ }^{4}$ Matia Fundazioa - Matia Instituto Gerontológico., Donostia, Spain

\section{0:1136/bmjqs-2013-002293.242}

Background Although legal and ethical aspects related to the care of people with dementia have been long neglected, current guidelines highlight its importance. Specifically, the advanced directives document (ADs) is a useful instrument in decisionmaking in non-competent patients. Despite the promotion of guidelines related to the use of $\mathrm{ADs}$, it is claimed that adherence is not as optimal as desired. An analysis of the barriers to implementation is therefore needed.

Objectives To explore health professionals' knowledge and attitudes towards the use of ADs in three different health settings and to evaluate their adherence to the established recommendations.

Methods A cross sectional, descriptive study by means of a selfadministered questionnaire was conducted with over 2,000 professionals working in dementia care in the Basque Country. On the other hand, the relevant recommendations from the ADs in cases of dementia are summarised and it is discussed whether professionals comply with them.

Results Data is currently being analysed and results will be available for presentation at GIN.

Discussion Adherence to CPG is a long discussed issue. Bringing ethical issues into the debate makes it more complex, since not only the knowledge but the personal values are in place. That may explain why ethical and legal related recommendations and clinical practice differ considerably and why the use of ADs in the real practice remains a taboo.

Implications for Guideline Developers/Users Knowing the barriers to comply with $\mathrm{ADs}$ may help to put the mechanism in place to reduce the gap between theory and practice.

\section{P291 IS THE TRAINING PROVIDED TO PROFESSIONALS CARING FOR PEOPLE WITH ALZHEIMER'S DISEASE ADEQUATE ACCORDING TO CPG RECOMMENDATIONS?}

${ }^{1} \mathrm{G}$ Villanueva, ${ }^{1} \mathrm{M}$ López-Argumedo, ${ }^{1} \mathrm{E}$ Reviriego, ${ }^{2} \mathrm{E}$ Aguirreche Ollo, ${ }^{3} \mathrm{C}$ Gómez Poveda, ${ }^{4} A$ Elizondo, ${ }^{1} \mathrm{~L}$ Galnares-Cordero, ${ }^{1} \mathrm{R}$ Fuentes Gutiérrez. 'Basque Office for Health Technology Assessment, OSTEBA-EKU, Bilbao, Spain; ${ }^{2}$ Centro de rehabilitación neuropsicológica Arrigunaga, Bilbao, Spain; ${ }^{3}$ Residencia Fundación Miranda, Bilbao, Spain; ${ }^{4}$ Matia Fundazioa - Matia Instituto Gerontológico, Donostia, Spain

\section{0:1136/bmjqs-2013-002293.243}

Background Despite the rapid increase in the knowledge of epidemiology, genetics, risk factors and underlying neuropathological mechanisms of Alzheimer's disease (AD) and the rising number of consensus statements and guidelines for its diagnosis and treatment, little has been done concerning the training of the involved professionals. In particular, the European ALCOVE project (Alzheimer COOperative valuation in Europe) has indeed addressed this issue. Therefore there is a need to assess to what extent professionals in the Basque Country are receiving the recommended education.

Objectives 1. To compare the current training practices in dementia in the Basque Country with the recommendations proposed by ALCOVE. 2. To propose region-specific recommendations on the education of professionals working with patients with $\mathrm{AD}$ (neurologists, psychiatrists, primary care providers, nurses).

Methods A questionnaire (both electronic and paper version) was distributed to over 2,000 professionals in the Basque Country in early 2013. The results will be compared with the data arising from the ALCOVE project.

Results Collected data is currently being analysed and final results will be available for presentation at GIN.

Discussion Available guidelines recommend that professionals caring for patients with $\mathrm{AD}$ and their families should receive formal education and professional training. However, existing educational programmes might not adhere to these recommendations. Also there might be barriers for these programmes to be correctly implemented.

Implications for Guideline Developers/Users Specific training in dementia should be included in the medical schools' curriculum in every country given that $\mathrm{AD}$ affects an ever increasing number of elderly people worldwide. 